\title{
Pengaruh Media Pembelajaran Audio Visual Video MYOB terhadap Hasil Belajar MYOB
}

\author{
Anggono \\ Politeknik IT\&B Medan \\ anggono50@gmail.com

\section{Effi Aswita Lubis} \\ Universitas Negeri Medan \\ effiaswita23@gmail.com
}

\begin{abstract}
Abstrak Tujuan penelitian ini adalah untuk mengetahui pengaruh media pembelajaran audio visual video MYOB versi 18 terhadap hasil belajar MYOB siswa kelas XI - Akuntansi. Penelitian ini dilaksanakan di SMK Negeri I Medan T.P 2015/2016. Populasi penelitin berjumlah 144 siswa. Teknik pengambilan sampel menggunakan cluster random sampling dengan jumlah sampel sebanyak 35 siswa. Jenis penelitian ini adalah pra - eksperimen dengan rancangan penelitian one group pre-test post-test. Teknik pengumpulan data menggunakan tes hasil belajar. Sebelum tes hasil belajar diberikan kepada sampel sesungguhnya terlebih dahulu di uji tingkat validitas, realibilitas, daya beda soal, dan tingkat kesukaran soal. Teknik analisis data pada penelitian ini yaitu: uji normalitas dan uji t sampel berpasangan. Hasil penelitian media audiovisual video MYOB versi 18 berpengaruh positif dan signifikan terhadap hasil belajar MYOB Siswa Kelas XI Akuntansi di SMK Negeri I Medan T.P 2015/2016
\end{abstract}

Kata Kunci Hasil Belajar MYOB, Media Pembelajaran Audio Visual, Video MYOB versi 18

\begin{abstract}
Abstrak
The purpose of this research is to know the effect of audio visual instructional media $M Y O B$ video version 18 towards student's MYOB learning outcomes in XI-Accounting. The research was conducted at SMK Negeri I Medan A.P 2015/2016. The population of this research was the entire XI - Accounting which was consist four classes with 144 students. The sample of this research is 35 students, which were determined by cluster random sampling. This research is classified as pre - experimental with one group pre-test post-test design. Test is being use to collect data in this research. Before test give to real samples, the test was tested using validity, reliability, discriminating power, and the difficulty of test. The data analysis techniques in this research are normality test and paired sample t test. The result of the research is there is a positive and significant effect of audiovisual instructional media MYOB video version 18 towards student's MYOB learning outcomes in XI Accounting class at SMK Negeri I Medan A.P 2015/2016
\end{abstract}

Kata Kunci $\quad M Y O B$ Learning Outcome, Audio Visual Instructional Media, MYOB Video version 18

\section{PENDAHULUAN}


Dalam rangka menciptakan sumber daya manusia yang berkualitas, tangguh dan memiliki daya saing yang tinggi, maka diperlukan pendidikan yang berkulitas baik. Salah satu upaya pemerintah Indonesia dalam menciptakan pendidikan yang berkualitas baik adalah mengganti kurikulum tingkat satuan pendidikan (KTSP) dengan kurikulum 2013.

Dalam peraturan menteri pendidikan dan kebudayaan republik Indonesia nomor 70 tahun 2013 tertulis bahwa kurikulum 2013 berbeda dengan kurikulum tingkat satuan pendidikan (KTSP). Perbedaan yang paling mencolok adalah pendekatan pembelajaran yang digunakan pada kedua kurikulum tersebut. Kurikulum 2013 mengadopsi pendekatan student center learning (SCL). Pada pendekatan student center learning (SCL), siswa sendiri yang harus aktif dalam belajar, sedangkan tugas guru hanya sebagai pembimbing siswa dalam mencapai tujuan pembelajaran. Sebaliknya pada kurikulum tingkat satuan pendidikan (KTSP), pendekatan yang dipakai adalah teacher center learning (TCL). Pada pendekatan ini, gurulah yang berperan aktif dalam mengajari siswa dalam mencapai tujuan pembelajaran (Menteri Pendidikan Dan Kebudayaan Indonesia, 2013).

Dari hasil observasi di SMK Negeri 1 Medan yang dilakukan pada tanggal 08 Januari 2016 sampai 31 Januari 2016, diperoleh informasi dari guru bahwa pada SMK Negeri 1 Medan menggunakan kurikulum 2013 dan ditemukan juga bahwa ada guru pada mata pelajaran MYOB di kelas XI Akuntansi masih menggunakan teacher learning center. Pendekatan ini masih digunakan dikarenakan siswa belum mampu belajar secara mandiri dalam pembelajaran serta memiliki anggapan bahwa guru adalah sumber belajar utama bagi siswa. Pandangan siswa yang keliru terhadap pembelajaran membuat tujuan pembelajaran sering tidak tercapai karena guru harus mengajari mereka satu per satu.

Pendekatan pembelajaran yang tidak sesuai dengan tuntutan kurikulum berdampak pada hasil belajar MYOB siswa kelas XI Akuntansi di SMK Negeri I Medan T.P 2015/2016. Hasil belajar MYOB siswa kelas XI Akuntansi selama tiga kali ulangan harian banyak siswa yang tidak lulus. Untuk melihat jumlah siswa yang lulus dan tidak lulus pada ulangan harian dapat dilihat pada tabel dibawah ini:

Tabel 1

Hasil Ulangan Siswa

\begin{tabular}{|l|c|c|}
\hline Ulangan Harian & $\begin{array}{c}\text { Jumlah Siswa Yang } \\
\text { Lulus }\end{array}$ & Jumlah Siswa Yang Tidak Lulus \\
\hline Pertama & 91 & 53 \\
\hline Kedua & 80 & 64 \\
\hline Ketiga & 73 & 71 \\
\hline
\end{tabular}

(Sumber Data: Daftar Nilai Kelas XI Akuntansi SMK Negeri 1 Medan T.P 2015/2016)

Kelas XI Akuntansi SMK Negeri 1 Medan T.P. 2015/ 2016 terdiri 144 siswa yang terbagi menjadi empat kelas yaitu XI Ak 1, XI Ak 2, XI Ak 3 dan XI Ak 4. Pada ulangan harian pertama, siswa yang lulus sebanyak 91 siswa, sedangkan siswa yang tidak lulus berjumlah 53 siswa. Pada ulangan harian kedua, jumlah siswa yang tidak lulus sebanyak 64 siswa, sedangkan siswa yang lulus sebanyak 80 siswa. Pada ulangan harian ketiga siswa yang lulus sebanyak 73, sedangkan siswa yang tidak lulus sebanyak 71 siswa. Dengan demikian, dapat disimpulkan bahwa jumlah siswa yang tidak lulus semakin banyak setiap kali diadakan ulangan harian, dengan kata lain 
semakin dalam materi yang diajarkan, semakin banyak pula siswa yang tidak lulus dalam ulangan harian.

Hasil wawancara dengan beberapa siswa yang duduk di kelas XI Akuntansi tentang hasil belajar MYOB mereka yang rendah. Beberapa siswa mengatakan bahwa mereka bergantung kepada guru pada pelajaran MYOB dikarenakan sumber belajar yang mereka dapatkan berupa buku cetak yang tidak minat belajar. Buku cetak siswa hanya berisi teori - teori tanpa ada pratek langsung dari buku. Hal ini yang menyebabkan siswa lebih menyukai bertanya langsung kepada guru.

Media pembelajaran audio visual diduga mampu mengatasi permasalahan yang dihadapi guru. Media pembelajaran audio visual adalah media pembelajaran yang mengeluarkan visual dan suara. Media pembelajaran audio visual mampu menyampaikan materi pembelajaran dengan efektif, efisien serta menarik perhatian siswa. Media pembelajaran audio visual juga diduga mampu meningkatkan hasil belajar MYOB siswa. Hal ini didukung dari penelitian yang terdahulu yang meyimpulkan bahwa penggunaan media pembelajaran audio visual mampu meningkatkan hasil belajar siswa di SMK Muhammadiyah Purwodadi Tahun Pelajaran 2013/2014 (Sholihin \& Susanto, 2015).

\section{LANDASAN TEORI}

\section{II.1. Media Pembelajaran Audio Visual}

Media pembelajaran audiovisual adalah media atau alat yang selain mengandung unsur suara juga mengandung unsur gambar yang dapat dilihat, sebagai contoh media pembelajaran ini yaitu: video, film, slide suara, dan sebagainya (Sanjaya, 2014).

Kelebihan media pembelajaran ini ialah dapat mengasah segala aspek indera pendegar, pengelihatan dan peraba, sedangkan kelemahannya adalah media pembelajaran ini termasuk media yang mahal dan penerapannya harus memiliki kemampuan yang optimal (Lubis, 2015).

\section{II.2. Video MYOB}

Pada awalnya video digunakan untuk tujuan komersial dan hiburan, namun setelah pakar teknologi pendidikan melakukan pengembangan, pada masa sekarang video memiliki kegunaan yang lebih luas yaitu untuk pembelajaran. Video memiliki kegunaan untuk mempengaruhi pesan yang bersifat informatif, edukatif, dan instructional (Sadiman, Rahardjo, Haryono, \& Rahardjito, 2012). Selanjutnya, MYOB adalah perangkat lunak akuntansi yang berfungsi mengelola transaksi keuangan, mengerjakan siklus akuntansi dan menghasilkan laporan keuangan dimana dapat diterapkan diperusahaan jasa, dagang, dan manufaktur (Mahmudi \& Charter, 2010). Jadi video MYOB adalah media audio visual yang berisi materi pembelajaran MYOB yang digunakan untuk menampilkan pesan yang bersifat informatif, edukatif maupun instructional dalam pembelajaran MYOB.

Kelebihan video terdiri dari beberapa yaitu mampu memberikan pengalaman pada siswa, dapat menampilkan suatu proses secara tepat, dapat memotivasi siswa untuk melakukan diskusi, dapat menyajikan fenomena yang berbahaya dan dapat digunakan pada kelompok besar, sedangkan kelemahannya terdiri dari beberapa yaitu pengadaan video memerlukan biaya yang mahal, tidak semua siswa mampu mengikuti gambar video yang bergerak terus, dan sulit mendapatkan video yang sesuai dengan tujuan dan materi pelajaran, kecuali video tersebut dikembangkan sendiri (Arsyad, 2013). 


\section{II.3. Hasil Belajar MYOB}

Hasil belajar merupakan wujud pencapaian peserta didik; sekaligus merupakan lambang keberhasilan pendidik dalam membelajarkan peserta didik (Yusuf, 2015). Selanjutnya, MYOB adalah aplikasi komputer akuntansi yang sangat popular dikalangan para akunting dan pengusaha yang digunakan untuk pembuatan laporan akuntansi bagi bisnis yang mereka jalankan (Mansoor, 2013).

Jadi hasil belajar MYOB adalah wujud pencapaian peserta didik setelah menerima pengalaman belajar MYOB yang dapat berupa perubahan perilaku kognitif, psikomotorik, dan afektif, serta sekaligus merupakan lambang keberhasilan pendidik dalam membelajarkan MYOB kepada peserta didik.

\section{II.4. Hipotesis Penelitian}

Hipotesis penelitian ini adalah media audiovisual video MYOB versi 18 berpengaruh positif terhadap terhadap hasil belajar MYOB siswa kelas XI Akuntansi di SMK Negeri I Medan T.P $2015 / 2016$.

\section{METODE PENELITIAN}

Penelitian ini dilaksanakan di SMK Negeri I Medan T.P 2015/2016 pada semester genap dengan populasi seluruh siswa kelas XI - Akuntansi yang terdiri dari empat kelas yang berjumlah 144 siswa. Teknik pengambilan sampel menggunakan cluster random sampling terdiri dari dua tahap. Tahap pertama pemilihan kelas yang terpilih adalah kelas XI Ak 2, selanjutnya pada tahap kedua terpilih secara acak 35 siswa dari 38 siswa. Jenis penelitian ini adalah pra - eksperimen. Rancangan pra - eksperimen yang digunakan pada penelitian adalah one group pre-test post-test. Rancangan one group pre-test post-test dibawah ini yaitu (Setyosari , 2015):

Tabel 2

Desain One Group Pre-test Post-test

\begin{tabular}{|c|c|c|}
\hline Pretest & Treatment & Posttest \\
\hline$O_{1}$ & $\mathrm{X}$ & $O_{2}$ \\
\hline
\end{tabular}

Keterangan:

O1 : Nilai Pre-Test

$\mathrm{O} 2 \quad$ : Nilai Post - Test

X : Media pembelajaran audio visual video MYOB versi 18

Teknik pengumpulan data yang digunakan adalah tes hasil belajar. Tes hasil belajar yang diberikan adalah bentuk pilihan berganda yang berjumlah 20 soal. Agar tes hasil belajar mampu mengukur hasil belajar dengan optimal, maka dilakukan uji validitas, realibilitas, daya beda soal, dan tingkat kesukaran soal. Teknik analisa data pada penelitian ini terdiri dari statistik deskriptif, uji pra - syarat dan statistik inferensial. Statistik deskriptif terdiri dari mean, standar deviasi, varians, nilai minimum dan nilai maksimum, selanjutnya uji pra - syarat dilakukan dengan uji normalitas dan untuk statistik inferensial menggunakan uji t sampel berpasangan.

\section{HASIL PENELITIAN DAN PEMBAHASAN}

\subsection{Hasil Penelitian}

Hasil penelitian yang pertama dipaparkan adalah statistik deskriptif. Statistik deskriptif dijabarkan dalam tabel dibawah ini yaitu: 
Tabel 3

Statistik Deskriptif

\begin{tabular}{|l|c|c|}
\hline \multicolumn{1}{|c|}{ Deskripsi } & Pretest & Posttest \\
\hline Rata - Rata & 67,1429 & 84,1429 \\
\hline Standar Deviasi & 10,5917 & 8,78549 \\
\hline Varian & 112,185 & 77,185 \\
\hline Nilai Tertingi & 90 & 100 \\
\hline Nilai Terendah & 45 & 70 \\
\hline
\end{tabular}

Dari tabel 3 diatas dapat diketahui bahwa sebelum diterapkan media audio visual video MYOB versi 18, kelas XI Ak 2 memiliki rata - rata hasil belajar pre - test sebesar 67,1429, nilai standar deviasi sebesar 10,5917, nilai varian sebesar 112,185, nilai tertinggi sebesar 90 dan nilai terendah sebesar 45. Setelah diterapkan media pembelajaran audio media video MYOB versi 18 kelas XI Ak 2 mempunyai hasil belajar post - test menunjukkan nilai rata - rata sebesar 84,1429, nilai standar deviasi sebesar 8,78549, nilai varian sebesar 77,185, nilai tertinggi sebesar 100 dan nilai terendah sebesar 70. Dengan demikian dapat disimpulkan hasil belajar MYOB meningkat setelah diterapkan media pembelajaran audio visual video MYOB versi 18.

Setelah statistik deskriptif dipaparkan, selanjutnya dilanjutkan pada uji pra - syarat yaitu uji normalitas yaitu:

\section{Tabel 4}

Hasil Uji Normalitas

\begin{tabular}{|l|c|c|}
\hline Deskripsi & $\begin{array}{c}\text { Shapiro } \\
\text { Wilk }\end{array}$ & Keterangan \\
\hline Pre - test & 0,626 & Normal \\
\hline Post - test & 0,086 & Normal \\
\hline
\end{tabular}

Dari tabel diatas, diketahui bahwa nilai sig. Shapiro Wilk pre-test sebesar 0,626 dan nilai sig. Shapiro Wilk post - test sebesar 0,086 lebih tinggi dari nilai alpha yaitu 0,050. Dengan demikian dapat disimpulkan bahwa data hasil belajar pre - test dan post - test berdistribusi normal. Dengan demikian, syarat pengujian hipotesis menggunakan statistika parametrik terpenuhi.

Sesudah data berdistribusi normal, selanutnya dilakukan uji t sampel berpasangan, berikut dibawah ini merupakan hasil uji t sampel bepasangan :

Tabel 5

Hasil Uji t Sampel Berpasangan

\begin{tabular}{|c|c|c|}
\hline Deskripsi & Sig & $t_{\text {hitung }}$ \\
\hline Pretest - Posttest & 0,000 & 12,618 \\
\hline
\end{tabular}

Berdasarkan tabel diatas, nilai Sig. (2-tailed) sebesar 0,000 lebih kecil dari $\alpha=0,050$ atau $t_{\text {hitung }}$ sebesar 12,618 lebih besar dari $t_{\text {tabel }}=2,032$. Dengan demikian, maka dapat disimpulkan media audio visual video MYOB versi 18 berpengaruh positif dan signifikan terhadap hasil belajar MYOB Siswa Kelas XI Akuntansi di SMK Negeri I Medan T.P 2015/2016 .

\subsection{Pembahasan}

Media pembelajaran audio visual video MYOB versi 18 berpengaruh positif dan signifikan terhadap hasil belajar MYOB. Hal ini disebabkan penggunaan video MYOB versi 18 mampu 
menjelaskan proses pembuatan data perusahaan baru, daftar akun berserta cara penginputan transaksi keuangan dengan menarik dan menyenangkan, selain itu video MYOB versi 18 dapat diputar berulang kali oleh siswa ketika siswa belajar mandiri dirumah maupun diluar kelas dan materi pembelajaran yang disajikan dengan video MYOB versi 18 memberikan suasana belajar yang baru dan tidak monoton kepada siswa, sehingga materi pembelajaran lebih mudah dipahami oleh siswa.

Penggunaan video MYOB versi 18 pada pertemuan pertama dan kedua masih belum lancar, hal ini disebabkan guru dan siswa masih belum terbiasa menggunakan video MYOB versi 18 . Namun pada pertemuaan selanjutnya, suasana kelas sudah kondusif, antusias dan menyenangkan dikarenakan siswa sudah mulai terbiasa dengan penggunaan media pembelajaran audio visual video MYOB versi 18, begitu juga dengan guru pada pertemuan ketiga dan seterusnya guru sudah tidak canggung lagi dalam menggunakan media pembelajaran audio visual video MYOB versi 18.

Dari uraian sebelumnya, media pembelajaran audio visual video MYOB versi 18 mampu membantu guru dalam mengurangi ketergantungan siswa terhadap guru, hal ini terlihat siswa memutar kembali video MYOB versi 18 ketika siswa kurang paham, sehingga guru bisa lebih memusatkan perhatiannya kepada siswa lain yang memiliki kesulitan belajar. Dengan demikian, media pembelajaran audio visual MYOB versi 18 mampu menjadi alat bantu guru dalam mencapai tujuan pembelajaran.

Penelitian ini juga mengkonfirmasi kebenaran bahwa video dapat memotivasi siswa, video dapat digunakan untuk kelas yang memiliki jumlah siswa yang banyak, dan video dapat menyampaikan materi dengan cepat (Arsyad, 2013). Bila hasil penelitian ini dibandingkan dengan penelitian (Nugraha, Eko, \& Boenasir, 2014), (Mukminin \& Prihanto, 2014), (Fitrianingsih \& Musdalifah, 2015), (Rifain \& Suyitno, 2015), (Ula, Sutikno, \& Matsuri, 2015), serta (Sholihin \& Susanto, 2015). Hasil penelitian menunjukkan hasil yang sama yaitu media pembelajaran video mampu meningkatkan hasil belajar.

Penelitian ini sudah diusahakan seteliti mungkin agar mendapatkan hasil optimal, namun penelitian ini tidak terlepas dari keterbatasan penelitian yaitu waktu penelitian yang singkat dalam melihat hasil belajar MYOB yang diajarkan dengan media audio visual video MYOB versi 18 . Selain itu, penelitian ini menggunakan rancangan ekperimen yang sangat sederhana sehingga belum mampu mengetahui dengan jelas perbedaan hasil belajar MYOB yang diajarkan dengan media pembelajaran audio visual MYOB versi 18 dengan hasil belajar MYOB yang diajarkan tanpa media pembelajaran audio visual MYOB versi 18.

\section{KESIMPULAN}

Kesimpulan yang dapat diambil pada penelitian ini adalah media pembelajaran audio visual MYOB versi 18 berpengaruh positif dan signifikan terhadap hasil belajar MYOB siswa kelas XI - Akuntansi Di SMK Negeri I Medan T.P 2015/2016.

\section{SARAN}

Saran - saran yang dapat diberikan berdasarkan hasil penelitian ini adalah sebagai berikut: 
1) Untuk guru akuntansi yang akan mengajarkan kompetensi dasar membuat data perusahaan baru, daftar akun dan transaksi keuangan pada mata pelajaran MYOB dapat menggunakan media pembelajaran audio visual video MYOB versi 18 dalam upaya meningkatkan hasil belajar MYOB siswa.

2) Bagi peneliti selanjutnya yang mempunyai keinginan melakukan penelitian yang sejenis disarankan untuk menambah jumlah pertemuan agar mampu mengetahui dengan jelas perlakuan eksperimen media pembelajaran audio visual MYOB versi 18 dalam meningkatkan hasil belajar, selain itu peneliti selanjutnya direkomendasikan untuk mengunakan rancangan eksperimen yang memiliki kelas kontrol sehingga mampu mengetahui perbedaan hasil belajar MYOB yang menggunakan media pembelajaran audio visual MYOB versi 18 dengan hasil belajar MYOB yang tidak menggunakan media pembelajaran audio visual MYOB versi 18 .

\section{DAFTAR REFERENSI}

Arsyad, A. (2013). Media Pembelajaran . Jakarta: Rajawali Pers.

Fitrianingsih, R., \& Musdalifah. (2015). Efektivitas Penggunaan Media Video Pada Pembelajaran Pembuatan Strapless Siswa Kelas XII SMK 1 Jambu. Fashion and Fashion Education Journal, 4(1), 1-6.

Lubis, E. A. (2015). Strategi Belajar Mengajar. Medan : Perdana Publishing.

Mahmudi, A., \& Charter, N. (2010). Akuntansi Manufaktur Dan UKM. Jakarta: PT Elex Media Komputindo.

Mansoor, N. (2013). Akuntansi Dengan MYOB Untuk Pemula \& Orang Awam. Jakarta: Laskar Aksara.

Menteri Pendidikan Dan Kebudayaan Indonesia. (2013). Peraturan Menteri Pendidikan Dan Kebudayaan Republik Indonesia Nomor 70 Tahun 2013 Tentang Kerangka Dasar Dan Sturktur Kurikulum Sekolah Menegah Kejuruan / Madraah Aliyah Kejuruan. Jakarta, Indonesia: Kementrian Pendidikan Dan Kebudayaan Republik Indonesia.

Mukminin, Y. A., \& Prihanto, J. B. (2014). Penerapan Media Pembelajaran Audiovisual (Video) Terhadap Hasil Belajar Service Bawah Bola Voli (Studi pada Siswa Kelas V SDN Pademawu Barat I Kecamatan). Jurnal Pendidikan Olahraga dan Kesehatan, 02 (03), 595 $-598$.

Nugraha, A. A., Eko, B., \& Boenasir. (2014). Pengaruh Penggunaan Media Video Terhadap Hasil Belajar Siswa Pada Kompetensi Dasar Pengoperasian Mesin Bubut. Journal of Mechanical Engineering Learning, 3(1), 56-63.

Ribawati, E. (2015). Pengaruh Penggunaan Media Video Terhadap Motivasi Dan Hasil Belajar. Jurnal Candrasangkala, 01(01), 1-12.

Rifain, A., \& Suyitno. (2015). Pengembangan Video Pembelajaran Motor Starter Untuk Meningkatkan Kreatifitas Belajar Siswa Di SMK Muhammadiyah 1 Borobudur. Jurnal Pendidikan Teknik Otomotif, 05(01), 5-9. 
Sadiman, A. S., Rahardjo, R., Haryono, A., \& Rahardjito. (2012). Media Pendidikan Pengertian, Pengembangan, Dan Pemanfaatannya. Jakarta: Raja Grafindo Persada.

Sanjaya, W. (2014). Strategi Pembelajaran Berorientasi Standar Proses Pendidikan . Jakarta : Kencana.

Setyosari , P. (2015). Metode Penelitian Pendidikan \& Pengembangan. Jakarta : Kencana.

Sholihin, I., \& Susanto, A. (2015). Peningkatan Hasil Belajar Melalui Penggunaan Media Pembelajaran Audio Visual Pada SMK Muhammadiyah Puwodadi. Jurnal Pendidikan Teknik Otomotif, 05(01), 113-116.

Ula, I. R., Sutikno, \& Matsuri. (2015). Video Terjadinya Petir Sebagai Media Pembelajaran Fisika Untuk Meningkatkan Pemahaman Konsep Siswa pada Materi Listrik Statis. Seminar Nasional Fisika 2015. 04, pp. 1- 4. Jakarta: Universitas Negeri Jakarta.

Yusuf, A. M. (2015). Asesmen Dan Evaluasi Pendidikan . Jakarta: Kencana. 